\title{
Hipoksik Beyin Hasarlı Hastanın Palyatif Bakımda Takibi ve Semptomlarındaki İyileşme: Olgu Sunumu
}

\section{Follow-up of Hypoxic Brain Damaged Patient in Palliative Care and Improvement in Symptoms: A Case Report}

\author{
Nuray KIVANÇ TERZI 1 (D) , Dursun ÇADIRCI 1 (D) Şenay KOÇAKOĞLU 1 (D)
}

1 Harran Üniversitesi Tıp Fakültesi, Aile Hekimliği Anabilim Dalı, Şanlıurfa,Türkiye

Öz.

Kafa travması geçiren hastalarda, beyne oksijen transferi ve beynin oksijeni kullanımı arasında oluşan dengesizlik sonucunda hipoksi tablosu gelişir. Bu vaka sunumunda, palyatif bakım kliniğimizde yatırılarak takip edilen hipoksik beyin hasarı tanılı bir hasta ele alınmıştır. Yıllar içinde önemi daha da belirginleşen palyatif bakımda, multidisipliner yaklaşım esastır. Palyatif bakım, iyi bir semptomatik kontrol ile hastanın geri kalan yaşamını en iyi şekilde geçirebilmesini hedefler ve hasta yakınlarının tüm süreç boyunca desteklenmesi sağlanır. Bu vakada, palyatif bakım kliniğimizde hasta yakınları ile kurulan doğru iletişim ve destek ortamında, hastanın semptomlarında görülen değişiklikler aktarılmıştır. Amacımız palyatif bakımın terminal dönem hastalıklar dışında, uzun soluklu tedavi ve rehabilitasyon gerektiren hastalıklarda iyileştirici etkisini bir örnek üzerinde irdelemektir.

Anahtar kelimeler: Hipoksik beyin hasarı, Palyatif bakım, Rehabilitasyon, Travma

\section{Abstract}

In patients suffering from head injury, hypoxia occurs as a result of an imbalance between oxygen transfer to the brain and oxygen usage in the brain. In this case report, a patient diagnosed with hypoxic brain injury who was hospitalized in our palliative care clinic was discussed. In palliative care, the importance of which becomes more evident over the years, multidisciplinary approach is essential. Palliative care, with good symptomatic control, aims that the patient can spend the rest of his life in the best way and relatives of the patients are supported throughout the process. In this case, changes in the symptoms of the patient were reported in the correct communication and support environment established with the relatives of our patients in our palliative care clinic. Our aim is to examine the curative effect of palliative care in diseases requiring long-term treatment and rehabilitation, on an example, apart from terminal diseases.

Key words: Hypoxic brain damage, Palliative care, Rehabilitation, Trauma
Sorumlu Yazar I

Corresponding Author

Dr. Dursun ÇADIRCI

Harran Üniversitesi Tıp Fakültesi Aile Hekimliği Anabilim Dalı Osmanbey Kampüsü

63000 Şanlıurfa

Tel: +904143444839

e mail: drdcadirci@hotmail.com

Geliş tarihi / Received:

19.03.2020

Kabul tarihi / Accepted: 27.04.2020

DOI: $10.35440 /$ hutfd. 706367

Bu çalışma 25 Ekim-27 Ekim 2018 tarihleri arasında Ankara'da düzenlenen 17. Ulusal Aile Hekimliği Kongresinde sözlü bildiri olarak sunulmuştur. 


\section{Giriş}

Dünya Sağlık Örgütü (DSÖ)'ne göre palyatif bakımın tanımı, "Erken tanı ve kusursuz değerlendirmeyle sıkıntıların önlenmesi ve rahatlatılması, ağrının fiziksel, psikososyal ve ruhsal diğer sorunların tedavisi yoluyla yaşamı tehdit eden hastalıklarla ilişkili problemlerle yüzleşen hasta ve yakınlarının yaşam kalitesini iyileştiren bir yaklaşım" şeklinde yapılmıştır (1). Kafa travması sonrasında beyne oksijen transferi ve beynin oksijeni kullanımı arasındaki dengesizlik nedeniyle oluşan hipoksi, beyinde hasar tablosu gelişmesine neden olur (2).

Bu vaka sunumundaki amacımız, motorsiklet kazası sonrası hipoksik beyin hasarı tanısı alan bir hastaya palyatif bakım kliniğimizde uyguladığımız çok alanlı bakım ve hasta yakınları ile kurduğumuz iletişim sonucunda semptomlarında görülen değişiklikleri aktarmak ve palyatif bakımın ana prensiplerini vurgulamaktır.

\section{Olgu Sunumu}

Geçirdiği motorsiklet kazasının ardından bir ay süre ile yoğun bakımda yatıılarak tedavi edilen 31 yaşında erkek hasta, beslenme ve genel bakım desteği ihtiyacı olması üzerine palyatif bakım servisimizce devralındı. Hastanın kabulünde, bilinci kapalı, gözleri spontan açık olup sadece ağrılı uyarana yanıt veriyordu. Glasgow skoru 8 olarak değerlendirildi. Çevre ile anlamlı ilişkisi yoktu. Motor kuvvet, spastisite nedeni ile tam değerlendirilemedi. Sol klavikulasında kırık mevcuttu. Sol ayak daha belirgin olmak üzere ayaklar lateral pozisyondaydı ve zorlayarak ancak nötrale gelebiliyordu. Bilateral alt extremitelerde aşil gerginliği vardı. Üst ve alt extremitelerinde spastisiteler mevcuttu. Hastanın çekilen beyin tomografisinde (BT) hipoksik beyin hasarı açısından anlamlı olarak değerlendirilen enfarkt alanları vardı.

Hastanın tedavisinde multidisipliner yaklaşım uygulandı. Hasta belirli aralıklar ile nöroloji, fizik tedavi, enfeksiyon hastalıkları, beslenme ve diyetetik bölümleri ile konsülte edildi. Yutma güçlüğü olan hastanın beslenmesi başlangıçta nazogastrik sonda yardımı ile sağlandı. Spastisiteleri için kullanmakta olduğu baklofen dozu $10 \mathrm{mg}$ 4x1'e çıkarıldı. Karaciğer fonksiyon testleri (KCFT) ve hipotansiyon açısından yoğun takibe alındı. Haloperidol $2 \mathrm{mg} 3 \times 5$ damla başlandı. Üst extremiyete istirahat splinti, alt extremiteye istirahat ayak bileği ortezi (AFO) uygulandı. Günde 3 kere pasif ROM (range of motion) hareketlerine başlandı. Kilo kaybı gelişmiş olan hasta, kademeli olarak arttırılarak yüksek enerjili mama ile beslendi. 5 günlük omega 3 ve multivitamin desteği verilmesi planlandı. Tedavinin ilerleyen günlerinde KCFT değerlerinde yükselme olması üzerine baklofen dozu $2 \times 1$ 'e indirildi ve doz azaltılarak kesildi. Tizanidin $2 \mathrm{mg}$ 1x1, essitalopram $10 \mathrm{mg}$ 1x1 dozunda tedaviye eklendi. Servisimize kabulünde epileptik kasılmaları için almakta olduğu fenitoin tedavisinin yerine levetirasetam $2 \times 500 \mathrm{mg}$ başlandı.
Tedavinin 28. gününde bilinci açılan hastanın, göz teması kurmayı başardığı gözlendi. Yutma reflekslerinin iyi olması üzerine, perkütan endoskopik gastrostomi (PEG) açılma planı ertelendi ve oral beslenme gündeme geldi. Tedavinin 52. gününde Rejim 1'e başlanan hastanın bu süre içerisinde çevresine olan ilgisi arttı. "Beni duyuyorsan gözlerini kırp" ya da "elimi sık" gibi basit komutlara yanıt vermeye başladı. Birkaç gün içinde kontrollü olarak Rejim 2'ye geçildi. Palyatif kliniğimize yatışının 60 . gününde ise hasta "acı", "iyi", "evet" gibi basit kelimeler ile konuşmaya başladı. Olası bir enfeksiyonu önlemek için spontan idrar yapabileceği öngörülen hastanın intauretral kateteri çıkarıldı ve glob açısından yakın takibe alındı.

Tedavinin her aşamasında hasta yakınlarına ayrıntılı bilgi verildi. Destek ve motivasyonlarının hastanın sağ kalım ve hayat kalitesini arttırma yönünde etkinliği vurgulandı. İleriki yaşamında hastaya evde bakım verme konusunda sıkıntı yaşamamaları için hasta yakınlarına gerekli görülen konularda eğitim verildi ve interaktif uygulama yapıldı. Verilen eğitimler doğrultusunda dekübitis ülseri gelişmesinin önlenmesi ve tedavisi için hastanın pozisyon değişikliğinin yapılması, postural drenaj, aspirasyon, alt bezi değiştirilmesi, ağız bakımı, vücut temizliği fizik tedavi rehabilitasyon uzmanlarınca kendilerine önerilen primer egzersizlerin yaptırıması, hastanın beslenmesi, yara bakımı gibi konularda hasta yakınlarının destek sunmaları, bu arada kendilerinin de tecrübe kazanmaları sağlandı. Maddi yönden destek alabilmeleri için planlanmış olan 'evde hasta bakım ücreti'nden nasıl faydalanabilecekleri konusunda bilgi verildi. Uykusuzluk, depresyon, anksiyete yönünden değerlendirilen hasta yakınlarına bu konularda danışmanlık verildi ve gerekli hallerde ilaç tedavisi önerildi.

Hastamı tedavisinin 65. gününde "televizyonu göster", "kolunu kaldır", "burnuna dokun" gibi komutları yerine getirebilir duruma geldi. Palyatif bakım kliniğimize kabulünde Glasgow koma skoru (GKS) 8 olarak değerlendirilen, yatışının 72. gününde GKS 15 olarak fizik tedavi ve rehabilitasyon kliniğine devredilen hastanın palyatif bakım desteği sürdürüldü. Tedavisinin 90 . gününde anlamlı, tam cümleler kurabilmeye ve destek ile yürümeye başladı. Düzenli olarak kontole gelmesi planlanan hasta fizik tedavi ve rehabilitasyon bölümü tarafından takip önerileri ile taburcu edildi.

\section{Tartışma}

Palyatif bakımına, mümkün olan en erken zamanda başlanan hastaların, standart bakım alan hastalara oranla ortalama yaşam sürelerinin daha uzun olduğu, bu hastalarda psikolojik sorunların daha az görüldüğü, yaşam kalitelerinin iyilestiği tespit edilmiştir (3). Hastamızda da erken palyatif bakım desteği ile, hayatta kalma, fiziksel ve ruhsal iyilik hali bakımlarından olumlu gelişmeler kaydedilmiştir.

Palyatif bakım, iyileştirici veya ömür uzatan tedavilerin bitiminde uygulanabildiği gibi aynı anda da sağlanabilir. Bu olgu da, tedavi edici uygulamaları henüz devam ederken 
palyatif bakıma alınmıştır.

DSÖ tarafından 2014 yılında palyatif bakımın tanımı geliştirilerek, palyatif bakımın tüm hekimler için vicdani bir sorumluluk olduğu anlayışı kabul edilmiştir. Hasta yakınlarının tedavi sürecinde olduğu gibi yas dönemlerini de kapsayacak sekilde psikososyal, dini ve fiziki bakımlardan desteklenebilmeleri hususu da aynı dönemde bu hizmetler bütününe dahil edilmiştir $(1,4)$. Bu durum bize palyatif bakımın sadece hastayı değil hasta yakınlarını da kapsadığını açıkca göstermektedir $(1,5,6)$. Bu vakada tüm palyatif bakım ve rehabilitasyon sürecinde hedeflenen prensipler yerine getirilmiştir (Tablo 1) (7-9)

Tablo 1. Palyatif Bakımda Temel Prensipler (7-9)

\begin{tabular}{|c|c|}
\hline \multicolumn{2}{|c|}{ Palyatif Bakımda Temel Prensipler } \\
\hline Hastalığa ait s & $\begin{array}{ll}\text { unlarla baş etme } \\
\text { - } & \text { Fiziksel semptomlar } \\
\text { - } & \text { Psikiyatrik sorunlar } \\
\text { - } & \text { Manevi sorunlar } \\
\text { - } & \text { Sosyal sorunlar } \\
\text { - } & \text { Ekonomik sorunlar } \\
\text { - } & \text { Yaşam sonu intiyaçlar } \\
\text { - } & \text { Yas dönemi } \\
\end{array}$ \\
\hline Bakım süreci & 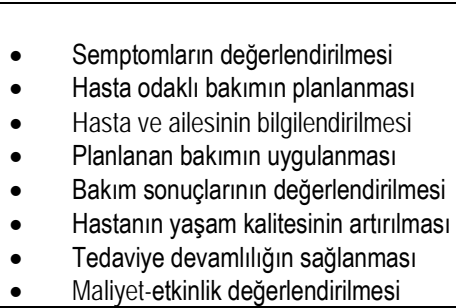 \\
\hline
\end{tabular}

Her basamakta verilen destek ve kurulan etkin iletişimle hasta yakınlarının hasta bakımına etkin şekilde dahil edilmesinin hastamızın semptomlarına olumlu yönde katkıları olduğu görülmüştür.

Yıllar içinde önemi daha da belirginleşen palyatif bakım, multidisipliner bir yaklaşımdır $(10,11)$. Palyatif bakımda önemli olan; hastaya spesifik bakım verilmesi, hasta yakını desteği, cok alanlı ekip çalışması ve etkili iletişimdir (11). Bakım ekibinde; algoloji, nöroloji, cerrahi ve onkoloji uzmanları, palyatif bakım hemşiresi, din görevlisi ve psikologlar yer alır (12). Aynı zamanda sivil gönüllüler de bu ekipte bulunmaktadır. Bu olguda da, farklı ekiplerle koordineli olarak çalışılmıştır.

Hastanelerde, aile sağlığı merkezlerinde hastaların kendi evlerinde ve Türkiye'de henüz bulunmamakla birlikte, yurt dışında, son dönem bakım evlerinde palyatif bakım hizmetleri sunulmaktadır (12). Palyatif bakım hizmetleri bir bakım kültürüdür ve hasta fiziksel, ruhsal, sosyal yönleri ile bir bütün olarak ele alınır. Ölümün doğal hayatın bir parçası olduğu gerçeğiyle hastaya destek olunmasının yanında, hasta yakınlarının intiyaçlarının da karşılanması esastır $(13,14)$.
Olgumuz, palyatif bakımın sadece terminal dönem hastalıklarda değil, Tablo 2'de görüldüğü gibi uzun soluklu tedavi ve rehabilitasyon gerektiren hastalıkların iyileştirilmesinde de aktif alarak kullanılma durumuna bir örnektir $(8,9)$.

Tablo 2. Palyatif Bakım Gerektiren Hastalıklar $(8,9)$.

\begin{tabular}{|cl|}
\hline Palyatif Bakım Gerektiren Hastalıklar \\
\hline - & Motor nöron hastalıkları ve ilerleyici nörolojik hastalıklar (Alzhei- \\
& mer, ALS) \\
- & Ileri dönem organ yetmezlikleri (Kalp, akciğer, böbrek, karaciğer, \\
& beyin) \\
- & Tedaviye yanıtsız kanserler \\
- & HIVIIIDS \\
- Çocuklarda genetiklkonjenital, ilerleyici hastalıklar
\end{tabular}

Beyin dokusunda oksijen parsiyel basıncının $10-15$ mmHg'nın altına inmesiyle beyinde infarkt gelişiminin söz konusu olduğu bildirilmiştir (15). Bu zeminde gelişebilen hipoksik iskemik beyin hasarı önemli bir morbidite ve mortalite nedenidir. Özellikle gençlerde ve yetmişbeş yaş üzerinde olan hastalarda kafa travması nedeniyle hipoksik hasar daha sıktır ve erkeklerde iki misli daha fazla görülmektedir (15). Türkiye'de trafik kazalarının halen en önde gelen beyin travması nedenlerinden olduğu bildirilmiş̧ir (16). Bu olguda literatür ile uyumlu şekilde, genç erkekte trafik kazası sonrası gelişmiş hipoksik beyin hasarı ele alınmıştır. Etkin bir palyatif bakımda, hasta yakınlarının da desteği ile multidisipliner bir yaklaşımla, hastaların yaşam kaliteleri ve sağ kalım süreleri artmaktadır. Palyatif bakım sadece terminal dönem hastalar için değil, hayatı tehdit edebilecek tüm hastalıklar için uygulanmalıdır. Palyatif bakım kliniğinde, hastanın iyi bir semptomatik kontrol ile geri kalan yaşamını en iyi sekilde geçirmesi ve hasta yakınlarının tüm süreç boyunca desteklenmesi gereklidir. Hasta yakınlarına düzenli olarak danışmanlık sağlanarak sorunları çözülebilmeli ve hastanın rehabilitasyon sürecine aktif olarak dahil edilmeleri sağlanmalıdır.

Hasta onamı: Çalışma için hastadan yazııı onam alınmıştır.

\section{Kaynaklar}

1. Organization WH. WHO definition of palliative care. [Internet homepage]

2002 [cited 01 September 2018]. Available from: http://www who int/cancer/palliative/definition/en/index $\mathrm{html}$.

2. Dilmen ÖK, Akçıl EF, Tunalı Y. Intensive Care Treatment in Traumatic Brain Injury Turk J Anaesthesiol Reanim. 2015;43(1):1-6.

3. Temel JS, Greer JA, Muzikansky A, Gallagher ER, Admane S, Jackson VA, et al. Early palliative care for patients with metastatic nonsmall-cell lung cancer. N Engl J Med. 2010;363(8):733-42.

4. Kabalak A, Öztürk H, Erdem AT, Akın S. SB Ulus Devlet Hastanesi'nde Kapsamlı Palyatif Bakım Merkezi Uygulaması. Çağdaş Tıp Dergisi. 2012;2(2):122-6.

5. Kabalak AA. Türkiye'de Palyatif Bakim; 2014, Güncel Gelişmeler, Gereksinimler. Anestezi Dergisi. 2014; 22 (3): 121 - 3 
6. Bag B. Almanya örneğinde sağlık sisteminde palyatif bakım uygulamaları. Turkish Journal of Oncology/Türk Onkoloji Dergisi. 2012;27(3):142-9

7. Sepúlveda C, Marlin A, Yoshida T, Ullrich A. Palliative care: the World Health Organization's global perspective. J Pain Symptom Manage. 2002;24(2):91-

8. Borasio GD. Translating the World Health Organization definition of palliative care into scientific practice. Palliative \& supportive care. 2011;9(1):1-2.

9. Kabalak AA, Öztürk H, Çağıl H. Yaşam sonu bakım organizasyonu: Palyatif bakım. Yoğun Bakım Dergisi. 2013;11(2):56-70.

10. Kumar V, Abbas A, Fausto N, Mitchell R. Robbins Temel Patoloji. 8. baskı. Bursa: Nobel Tıp Kitapevleri. 2007:739-50.

11. Kabalak A, Öztürk H, Çağıl H. End of life care organization; palliative care. Yoğun Bakım Dergisi. 2013;11(2):56-70.

12. Özçelik H, Fadıloğlu Ç, Uyar M, Karabulut B. Kanser hastaları ve aileleri için palyatif bakım. İzmir: Üniversite Opset. 2010.

13. Turgay G. Sağlık personelinin palyatif bakıma ilişkin görüşleri. Hemşirelik Programı Yayınlanmamış Yüksek Lisans Tezi, Başkent Üniversitesi Sağlık Bilimleri Enstitüsü Ankara, Türkiye. 2010:41-6.

14. Kıvanç MM. Türkiye'de palyatif bakım hizmetleri. Sağık Bilimleri ve Meslekleri Dergisi. 2017;4(2):132-5.

15. Johnston AJ, Steiner LA, Coles JP, Chatfield DA, Fryer TD, Smielewski $P$, et al. Effect of cerebral perfusion pressure augmentation on regional oxygenation and metabolism after head injury. Crit Care Med. 2005;33(1):189-95.

16. Korkmaz Dilmen Ö, Tunalı Y, Yentür E. Kafa travmalarında yoğun bakım tedavisi. Nobel Tıp Kitapevi, İstanbul. 2011:691-700. 